\title{
La multifunzionalità dell'agricoltura europea: riflessioni sul contributo del settore primario alla costruzione dell'identità culturale
}

Titolo Rivista: AGRICOLTURA ISTITUZIONI MERCATI

Autori/Curatori: Anna Carbone

Anno di pubblicazione: 2009 Fascicolo: 1,2 Lingua:

N. pagine: 12 Dimensione del file: $260 \mathrm{~Kb}$.

DOI: 10.3280/AIM2009-001010

(II DOI è il codice a barre della proprietà intellettuale: per saperne di più, clicca qui)

\section{Presentazione:}

La nota propone alcune riflessioni sul contributo che il settore primario può dare al mantenimento dell'identità culturale di un territorio ed al suo rafforzamento esplicando, così, una tra le diverse funzioni aggiuntive a quella primaria che vengono da più parti attribuite all'agricoltura nell'ampio dibattito sulla multifunzionalità del settore. Le idee riportate ruotano attorno al doppio nesso esistente tra le attività agricole - intese nel loro insieme e nella loro notevole multiformità - e l'identità culturale del territorio nel quale queste si svolgono. Le relazioni tra le due sfere sono profonde e si sviluppano, appunto, nei due sensi; vale a dire che se il modo di condurre/gestire le attività agricole è parte del patrimonio culturale specifico di un territorio, è anche vero che il patrimonio di conoscenze ed esperienze di un territorio influenza e determina, anche se ovviamente non in via esclusiva, il modo di fare agricoltura proprio di un'area. In particolare si mostra come siano espressamente alcune delle funzioni accessorie o aggiuntive a quella primaria, a ricoprire un ruolo particolarmente significativo in termini di contributo all'identità culturale di un territorio.

Keywords: Agricoltura, multifunzionalità, territorio, identità culturale 